\title{
Incidence of breast cancer subtypes in immigrant and non-immigrant women in Norway
}

Kirsti V. Hjerkind ${ }^{1 \dagger}$, Anna L. V. Johansson ${ }^{2,3 \dagger}$, Cassia B. Trewin ${ }^{1}$, Hege G. Russnes ${ }^{4,5}$ and Giske Ursin ${ }^{3,6,7^{*}}$ (D)

\begin{abstract}
Background: Breast cancer incidence differs between non-immigrants and immigrants from low- and middleincome countries. This study investigates whether immigrants also have different subtype-specific incidences.

Methods: We used national health registries in Norway and calculated subtype-specific incidence rate ratios (IRRs) for invasive breast cancer among women aged 20-75 and 20-49 years between 2005 and 2015. Immigrant groups were classified by country of birth broadly defined based on WHO regional groupings. Subtype was defined using estrogen receptor (ER), progesterone receptor (PR) and human epidermal growth factor 2 (HER2) status as luminal A-like (ER+ PR+ HER2-), luminal B-like/HER2- (ER+PR- HER2-), luminal B-like/HER2+ (ER+ PR any HER2+), HER2+ (ERPR-HER2+) and triple-negative breast cancer (TNBC) (ER-PR-HER2-).
\end{abstract}

Results: Compared to non-immigrants, incidence of the luminal A-like subtype was lower in immigrants from Sub-Saharan Africa (IRR 0.43 95\% Cl 0.28-0.66), South East Asia (IRR 0.63 95\% Cl 0.51-0.79), South Asia (IRR 0.67 95\% Cl 0.52-0.86) and Eastern Europe (IRR 0.86 95\% Cl 0.76-0.99). Immigrants from South Asia had higher rates of HER2 + tumors (IRR 2.02 95\% Cl 1.26-3.23). The rates of TNBC tended to be similar regardless of region of birth, except that women from South East Asia had an IRR of 0.54 (95\% Cl 0.32-0.91).

Conclusions: Women from Eastern Europe, Sub-Saharan Africa and Asia had different subtype-specific incidences compared to women from high-income countries (including non-immigrants). These differences in tumor characteristics between immigrant groups should be taken into consideration when planning preventive or screening strategies.

Keywords: Breast cancer subtypes, Immigrants, Incidence

\section{Background}

Breast cancer incidence varies across the world with agestandardized incidence rates (ASRs) above 73 cases per 100,000 person-years in Western Europe, the United States (U.S.), Canada, Australia and New Zealand and below 34 cases per 100,000 person-years in most of

\footnotetext{
*Correspondence: giske.ursin@kreftregisteret.no

${ }^{\dagger}$ Kirsti V. Hjerkind and Anna L. V. Johansson have contributed equally to this work

${ }^{3}$ Cancer Registry of Norway, Postbox 5313, 0304 Majorstuen, Oslo, Norway

Full list of author information is available at the end of the article
}

Sub-Saharan Africa, South Asia and South-East Asia [1]. Breast cancer can be subdivided into many different subtypes. Historically, these were defined using results on hormone receptor status (estrogen receptor [ER] and progesterone receptor [PR]) from immunohistochemical (IHC) analyses, and subsequently human epidermal growth factor 2 (HER2) status was added. Although these subtypes do not completely overlap the subtypes based on molecular expression studies [2], clinical practice still depends largely on these biomarkers. The different breast cancer subtypes represent distinct biological and clinical behaviors; some have more aggressive behavior and original author(s) and the source, provide a link to the Creative Commons licence, and indicate if changes were made. The images or other third party material in this article are included in the article's Creative Commons licence, unless indicated otherwise in a credit line to the material. If material is not included in the article's Creative Commons licence and your intended use is not permitted by statutory regulation or exceeds the permitted use, you will need to obtain permission directly from the copyright holder. To view a copy of this licence, visit http://creativecommons.org/licenses/by/4.0/. The Creative Commons Public Domain Dedication waiver (http://creativeco mmons.org/publicdomain/zero/1.0/) applies to the data made available in this article, unless otherwise stated in a credit line to the data. 
worse prognosis, and they respond differently to treatment options [3].

Studies from Africa indicate that African women have a high proportion of high grade tumors with an aggressive subtype, e.g., triple-negative breast cancer (TNBC) $[4,5]$. These tumors develop at a young age with an advanced stage distribution [5].

Many studies from the U.S. have demonstrated differences in incidence and survival across racial/ethnic groups (African-American, Hispanic and South-Asian women compared to non-Hispanic White women) [3, $6-11]$. These racial/ethnic groups are not directly comparable to the immigrant groups most commonly seen in Europe. However, an interesting question is whether there are similar differences in incidence and survival between European immigrant groups. We have previously reported that the incidence of stage-specific breast cancer was lower in immigrants than in non-immigrants in Norway [12]. Another Norwegian study found that immigrant women from low- and middle-income countries may have more advanced stage of breast cancer than non-immigrant women [13]. There are not many studies investigating subtype distribution among immigrant women with breast cancer in Western Europe. One smaller study found that Arab immigrants in Europe tend to develop cancer at a younger age with more luminal B-like and less luminal A-like subtypes than European women [14].

Socioeconomic status (SES) contributes to the racial/ ethnic disparities in breast cancer incidence and survival in the U.S. $[15,16]$. Such differences across SES could be due to health care access and could also be present across immigrant groups in Europe. On the other hand, there may be less of a difference when access to health care is universal, or where there are organized screening programs.

We previously reported that breast cancer incidence in Norway is higher in non-immigrant women and immigrant women from Western Europe and North America, and lower in women from Asia and Sub-Saharan Africa [17]. This study investigates breast cancer subtypes among immigrant groups using national health data in Norway from 2005 to 2015.

\section{Methods}

\section{Cohort data}

We used national Norwegian population registries to define a cohort of women which was linked with the Cancer Registry of Norway. Eligible women were registered as residents of Norway for twelve or more months during the period 2005-2015 $(n=3,329,630)$. We linked registries using the personal identification number (PIN) assigned to Norwegian-born at birth and to immigrants within six months after immigration. Information on vital status, including date of death and date of emigration, country of birth, date of immigration, and SES, such as education, household income and number of people in the household, was obtained from the Norwegian Population Registry at Statistics Norway.

\section{Definition of immigrant groups}

Immigrants were defined as individuals born outside of Norway with two foreign-born parents and a registered date of immigration (first generation immigrants), and non-immigrants were defined as individuals born in Norway or abroad with one or two Norwegian-born parents. Included in the non-immigrant population were individuals born in Norway of immigrant parents (second generation immigrants) ( $0.8 \%$ of the study population). The immigrants were classified according to their country of birth, which were collapsed into regions broadly defined consistent with the WHO regional groupings (Nonimmigrants; Immigrants from high-income countries including Western Europe, U.S.A., Canada, Australia, and New Zealand; Eastern Europe including Eastern Europe, Baltics and Balkan countries; Middle East including the Middle East and North Africa; Sub-Saharan Africa; South Asia; South-East Asia, Additional file 1: Table S1).

\section{Ascertainment of breast cancer diagnoses}

We identified breast cancer cases in the cohort during follow-up (January 12005 to December 31 2015) by linking the cohort to the Cancer Registry of Norway. A primary first invasive breast cancer was classified according to the 10th revision of the International Classification of Diseases (ICD-10), code C50. The Cancer Registry of Norway has since 1952 systematically collected notifications on cancer occurrence for the Norwegian population, reporting has been mandatory by law since the start, and the registry is considered to be close to complete [18].

From the 3,329,630 eligible women, we excluded 9741 women who had a previous diagnosis of breast cancer and 43,457 women from countries outside the included birth regions (South America and Eastern Asia due to few cases of breast cancer $[n=181])$. There were very few immigrants over 75 years in Norway and no subtype information available in this age group because of internal coding priorities at the Cancer Registry of Norway. Also, breast cancer is not common in individuals below the age of 20 years. Hence, we excluded women outside the age span 20-75 years leaving 1,921,487 women aged 20-75 years for the analysis. Since we did not have information on mode of detection in the current dataset, we also created a non-screened population by restricting to 
women aged 20-49 years who are not yet in screening age $(1,349,942$ women).

\section{Ascertainment of breast cancer subtypes}

Since 2005, the Cancer Registry of Norway collects information on hormone receptor status (ER, PR) and HER2 based on IHC results from pathology reports for women with breast cancer. From 2005 to January 2012, tumors were classified as ER- if there was $<10 \%$ reactivity. From February 2012, the threshold for ER- tumors was changed to $<1 \%$ reactivity as a result of change in the treatment protocols for patients attending clinics in Norway. PR- tumors were defined as those with reactivity of $<10 \%$, and $P R+$ tumors as those with reactivity $\geq 10 \%$ throughout the study period. HER2 expression status was routinely assessed with IHC and in general with in situ hybridization if the IHC results were borderline. Breast cancer subtypes were defined by IHC surrogates for molecular subtype according to the St Gallen 2013 criteria without using Ki67: luminal A-like (ER+PR+ HER2-) $n=12,568$, luminal B-like/HER2- (ER+PR- HER2-) $n=2984$, luminal B-like/HER2 $+($ ER + PR any HER2+) $n=2205$, HER2 $+($ ER- PR- HER2+) $n=1068$ and TNBC (ER- PR- HER2-) $n=2050[19,20]$. Subtype was set to "unknown" if any of ER, PR or HER2 were missing, or if ER- PR+ HER2 any.

\section{Statistical methods}

We used Poisson regression to estimate incidence rate ratios of invasive breast cancer by subtype and across regions of birth. Individuals were followed from age 20 or date of immigration, whatever occurred last, until diagnosis of first invasive breast cancer, death, emigration, age 76 or December 31, 2015, whichever occurred first. In the analysis of ages 20-49 the time-to-event was censored at age 50. The outcome was time to first breast cancer, hence in the estimated incidence of e.g., luminal A-like breast cancer, only women with a first breast cancer which was luminal A-like contributed events, while women with a first breast cancer which was another subtype or unknown were censored at first breast cancer. Time-to-event of the other subtypes was defined similarly. We estimated age-standardized incidence rates (ASRs) of subtype-specific breast cancer across regions of birth using the age distribution from the world standard population [21]. To compare the immigrant groups to non-immigrants, we estimated subtype-specific incidence rate ratios (IRRs) and confidence intervals (CIs) using Poisson regression models with regions of birth as the main covariate and with adjustment for age during follow-up in 5-year categories (20-24 years, 25-29 years, etc.) after time-splitting. The IRRs conveyed the relative risk of developing a particular subtype for an immigrant group compared with the non-immigrant population, and were estimated for ages $20-75$ and 20-49 years separately. In a second step, we also performed separate age-adjusted Poisson regression models by grade for all subtypes combined and within luminal A-like breast cancer (Table 3), and by ER status (Table 4).

\section{Additional analyses}

In sensitivity analyses, we adjusted the Poisson models for the most recently recorded education level before diagnosis, and categorized as compulsory ( $\leq 10$ years), secondary (11-13 years) or tertiary ( $\geq 14$ years) education. We also adjusted for average household income in quintiles, collected during the 5-year period prior to cancer diagnosis. We did not include either of these covariates in the final analyses since they did not change the results notably. To assess the impact of unknown subtype, we performed a sensitivity analysis restricting to the diagnosis period 2010-2015, where proportion of unknown subtype was low (6.8\%) among both immigrant and non-immigrant groups. The sensitivity analysis included all subtypes combined and the luminal A-like subtype. Finally, we restricted the analysis to women aged 20-40 years for all subtypes combined and for the luminal A-like subtype.

All statistical analyses were carried out using Stata version 15.1 (StataCorp. 2017. Stata Statistical Software: Release 15. College Station, TX: StataCorp LLC). The study was approved by the Regional Committees for Medical and Health Research Ethics (no. 2013/2376-17).

\section{Results}

The study population included 1,611,371 non-immigrant women $(88.7 \%$ of the person-years) and 310,116 immigrant women (11.3\% of the person-years) aged 20-75 years. Table 1 shows descriptive characteristics by immigrant subgroups. Mean age at immigration was similar across regions of birth, while the year of immigration, education level and income differed. Age at onset of breast cancer differed across regions of birth, likely reflecting differences in follow-up available due to year of immigration.

\section{Distribution of breast cancer subtypes}

The luminal A-like subtype was the most common both in non-immigrants and immigrant groups (Fig. 1a). The percentage of the luminal A-like subtype was especially high in non-immigrants and women from high-income countries, as well as women from Eastern Europe and the Middle East. The luminal B-like HER2+ subtype was more common in Sub-Saharan and in Asian women, and the HER2+ subtype more common in Asian women. The TNBC subtype was less common in non-immigrant 
Table 1 Characteristics of the study population by region of birth in women aged 20-75 years

\begin{tabular}{|c|c|c|c|c|c|c|c|}
\hline & \multirow{2}{*}{$\begin{array}{l}\text { Non-immigrants } \\
\text { Non-immigrants }\end{array}$} & \multicolumn{6}{|l|}{ Immigrants } \\
\hline & & High-income & Eastern Europe & Middle East & Sub-Saharan Africa & South Asia & South East Asia \\
\hline \multicolumn{8}{|l|}{ Total population } \\
\hline $\begin{array}{l}\text { Mean age (SD) at immigra- } \\
\text { tion }\end{array}$ & $\mathrm{N} / \mathrm{A}$ & $26.2(12.4)$ & $30.0(13.3)$ & $24.2(14.1)$ & $23.3(12.4)$ & $25.0(14.2)$ & $27.4(10.9)$ \\
\hline $\begin{array}{l}\text { Mean year (SD) of immigra- } \\
\text { tion }\end{array}$ & N/A & $1995(17)$ & 2005 (10) & $2003(9)$ & $2006(8)$ & $2000(12)$ & $2004(10)$ \\
\hline Education (\% tertiary) & 14.1 & 47.5 & 45.9 & 34.2 & 20.7 & 32.5 & 59.5 \\
\hline $\begin{array}{l}\text { Income (\% lowest quin- } \\
\text { tile)* }\end{array}$ & 14.0 & 31.7 & 41.6 & 62.2 & 75.4 & 44.3 & 39.3 \\
\hline \multicolumn{8}{|l|}{ Cases only } \\
\hline $\begin{array}{l}\text { Mean age (SD) when } \\
\text { diagnosed }\end{array}$ & $62.2(14.2)$ & $60.9(13.6)$ & $51.8(12.3)$ & $49.1(11.8)$ & $44.8(11.2)$ & $51.9(12.3)$ & $48.1(10.2)$ \\
\hline $\begin{array}{l}\text { Mean time (SD) from immi- } \\
\text { gration to diagnosis, years }\end{array}$ & N/A & $30.4(14.9)$ & $14.8(11.9)$ & $13.3(8.8)$ & $14.5(12.4)$ & $19.9(10.7)$ & $16.1(10.6)$ \\
\hline $\begin{array}{l}\text { Tumor grade (\% high grade } \\
3 \text { or } 4 \text { ) }\end{array}$ & 16.0 & 16.2 & 19.3 & 21.6 & 19.1 & 21.1 & 21.1 \\
\hline
\end{tabular}

High-income; Western Europe, USA, Canada, Australia and New Zealand, Eastern Europe; Eastern Europe, Baltics and Balkan, Middle East; Middle East and North Africa, SD; standard deviation, diag; diagnosis

*Highest level of education or income achieved during the study period

women and women from high-income countries and South-East Asian countries. These distributions were similar in the subgroup of women aged 20-49 years, although women from Asia had even more of the luminal B-like HER2+ subtype, and Sub-Saharan women more and Asian women less of the TNBC subtype (Fig. 1b). The percentage of unknown subtype was lowest in South Asian and South-East Asian women.

\section{Age-standardized rates within subtypes}

For the luminal-A like subtype, women from highincome countries had the highest ASR and Sub-Saharan women the lowest (Fig. 2a). Women from South Asia had the highest ASR of the HER2+ and TNBC subtypes, while women from Sub-Saharan Africa and South-East Asia had the lowest ASR. In ages 20-49 years, women from Sub-Saharan Africa had the lowest ASR of luminal A-like subtype, while women from South Asia and South-East Asia had the highest ASR of the luminal B-like HER2 + and HER2 + subtypes (Fig. 2b).

\section{Age-adjusted incidence rate ratios}

In models adjusted for age, women from high-income countries (IRR 1.07 95\% CI 0.99-1.16) and from the Middle-East (IRR 0.93 95\% CI 0.79-1.10) had similar rates of breast cancer compared to non-immigrants (Table 2). Women from Eastern Europe, Sub-Saharan Africa and Asia had significantly decreased rates of cancer compared to non-immigrants. This finding was similar in women aged 20-75 and women aged 20-49, however not significant in the latter. For the luminal A-like subtype, women from Sub-Saharan Africa had a lower rate compared to non-immigrant women, with an IRR of 0.43 (95\% CI $0.28-0.66$ ) in the age group $20-75$ years and an IRR of 0.44 (95\% CI $0.25-0.78)$ in the age group 20-49 years. Within the luminal B-like HER2- subtype, women from high-income countries aged 20-75 had a higher rate (IRR 1.29 95\% CI 1.06-1.57) compared to non-immigrant women, whereas women from the other regions had about the same rate, except women from South Asia who had a lower rate (IRR 0.49 95\% CI $0.27-$ 0.92 ). The pattern was similar among women aged 20-49, but the differences were not statistically significant in this group. Within the luminal B-like HER2+ subtype, immigrant women from all regions aged $20-75$ years had almost the same rates as non-immigrant women. Similar results were found in women aged 20-49, with the exception of South Asian women who had a significantly higher rate (IRR 1.72 95\% CI 1.06-2.78). Within the HER2+ subtype, Eastern European women aged 20-75 years had a significantly lower rate of the HER2+ subtype compared to non-immigrant women of the same age (IRR 0.51 $0.30-0.89)$. South Asian women aged 20-75 years had a significantly higher rate (IRR $2.0295 \%$ CI 1.26-3.23), as did South Asian women aged $20-49$ years (IRR 2.13 95\% CI 1.09-4.13). Within the TNBC subtype, immigrant women from the different regions had almost the same rate as non-immigrant women. The exception was women from South-East Asia, who had half the rate compared to non-immigrant women (20-75 years: IRR 0.54 

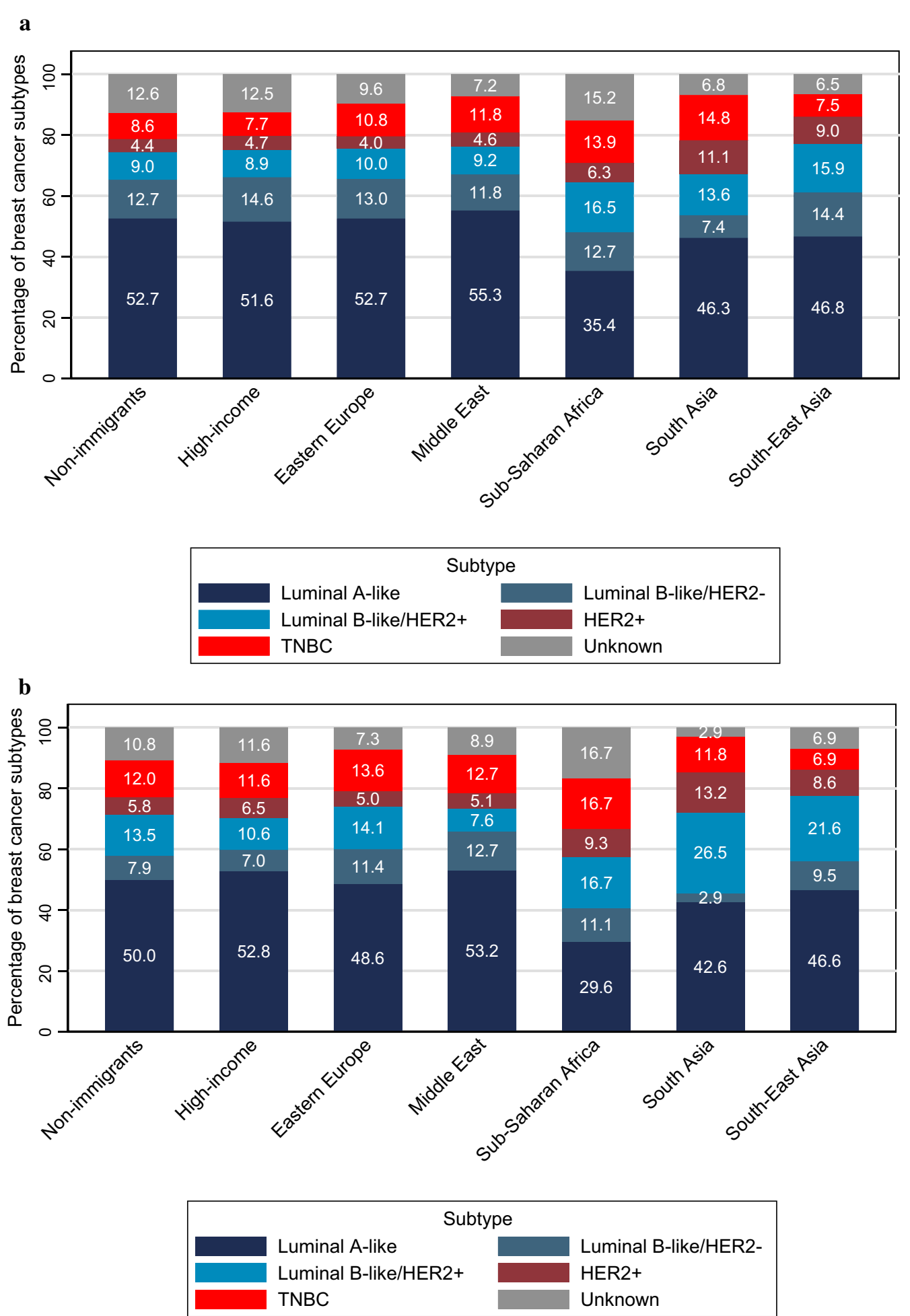

Fig. 1 a Distribution of subtypes within regions of birth in women aged 20-75 years. b Distribution of subtypes within regions of birth in women aged 20-49 years. High-income; Western Europe, USA, Canada, Australia and New Zealand, Eastern Europe; Eastern Europe, Baltics and Balkan, Middle East; Middle East and North Africa, TNBC; triple-negative breast cancer 

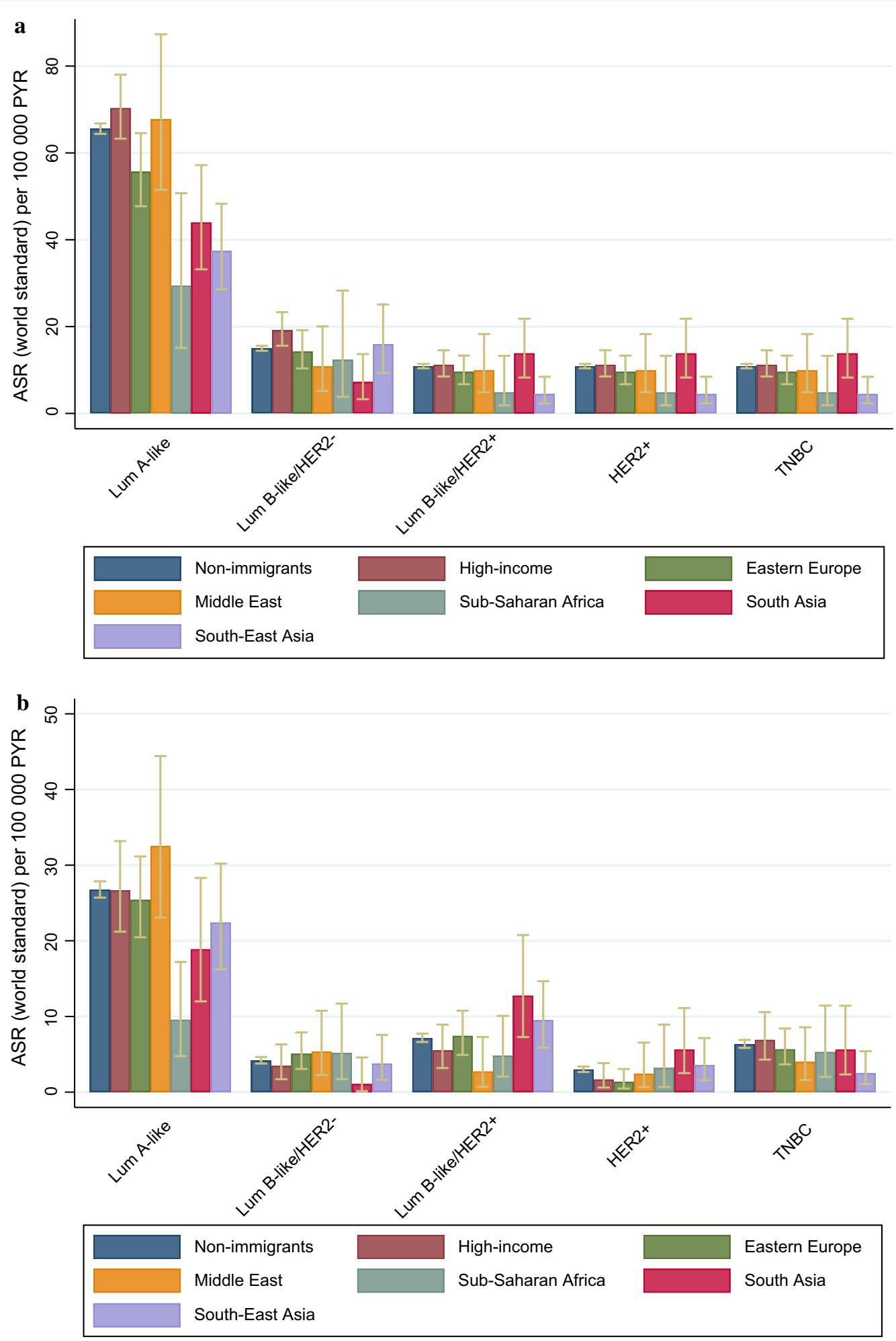

Fig. 2 a Age-standardized (world standard) incidence rates for different subtypes by region of birth in women aged 20-75 years. $\mathbf{b}$ Age-standardized (world standard) incidence rates for different subtypes by region of birth in women aged 20-49 years. ASR; age-standardized rate, PYR; person years, High-income; Western Europe, USA, Canada, Australia and New Zealand, Eastern Europe; Eastern Europe, Baltics and Balkan, Middle East; Middle East and North Africa, Lum A; luminal A-like, Lum B; luminal B-like, TNBC; triple-negative breast cancer 
Table 2 Incidence Rate Ratios (IRRs) for country of birth and invasive breast cancer subtypes

\begin{tabular}{|c|c|c|c|c|}
\hline & \multicolumn{2}{|l|}{ Age 20-75 } & \multicolumn{2}{|l|}{ Age 20-49 } \\
\hline & Cases/PYR & IRR (95\% CI) & Cases/PYR & IRR (95\% CI) \\
\hline \multicolumn{5}{|l|}{ All subtypes } \\
\hline Non-immigrants & $21,682 / 14608517$ & 1.00 (ref) & $4750 / 8335077$ & 1.00 (ref) \\
\hline High-income & $675 / 477618$ & $1.07(0.99-1.16)$ & $154 / 305153$ & $0.94(0.80-1.10)$ \\
\hline Eastern Europe & $417 / 593550$ & $0.85(0.77-0.93)$ & $195 / 486627$ & $0.90(0.78-1.04)$ \\
\hline Middle East & $136 / 176786$ & $0.93(0.79-1.10)$ & $69 / 147450$ & $0.97(0.77-1.23)$ \\
\hline Sub-Saharan Africa & $60 / 152194$ & $0.62(0.48-0.80)$ & $43 / 136880$ & $0.75(0.56-1.02)$ \\
\hline South Asia & 139/180867 & $0.78(0.66-0.92)$ & $61 / 139461$ & $0.87(0.68-1.12)$ \\
\hline South-East Asia & $178 / 284409$ & $0.71(0.61-0.82)$ & $101 / 232898$ & $0.85(0.70-1.04)$ \\
\hline \multicolumn{5}{|l|}{ Luminal A-like } \\
\hline Non-immigrants & $11,732 / 14608517$ & 1.00 (ref) & $2418 / 8335077$ & 1.00 (ref) \\
\hline High-income & $366 / 477618$ & $1.08(0.97-1.20)$ & $84 / 305153$ & $1.03(0.83-1.28)$ \\
\hline Eastern Europe & $222 / 593550$ & $0.86(0.76-0.99)$ & $99 / 486627$ & $0.95(0.77-1.16)$ \\
\hline Middle East & $81 / 176786$ & $1.06(0.85-1.32)$ & $41 / 147450$ & $1.18(0.86-1.60)$ \\
\hline Sub-Saharan Africa & 21/152194 & $0.43(0.28-0.66)$ & $12 / 136880$ & $0.44(0.25-0.78)$ \\
\hline South Asia & $63 / 180867$ & $0.67(0.52-0.86)$ & $25 / 139461$ & $0.73(0.49-1.08)$ \\
\hline South-East Asia & $83 / 284409$ & $0.63(0.51-0.79)$ & $46 / 232898$ & $0.79(0.59-1.06)$ \\
\hline \multicolumn{5}{|l|}{ Luminal B-like/HER2- } \\
\hline Non-immigrants & $2767 / 14608517$ & 1.00 (ref) & $377 / 8335077$ & 1.00 (ref) \\
\hline High-income & $102 / 477618$ & $1.29(1.06-1.57)$ & $11 / 305153$ & $0.85(0.46-1.54)$ \\
\hline Eastern Europe & $55 / 593550$ & $1.02(0.78-1.33)$ & $21 / 486627$ & $1.20(0.77-1.87)$ \\
\hline Middle East & 15/176786 & $0.97(0.58-1.61)$ & $8 / 147450$ & $1.41(0.70-2.83)$ \\
\hline Sub-Saharan Africa & 9/152194 & $0.93(0.48-1.80)$ & $6 / 136880$ & $1.30(0.58-2.92)$ \\
\hline South Asia & 10/180867 & $0.49(0.27-0.92)$ & 2/139461 & $0.36(0.09-1.43)$ \\
\hline South-East Asia & 26/284409 & $0.97(0.66-1.44)$ & 9/232898 & $0.95(0.49-1.84)$ \\
\hline \multicolumn{5}{|l|}{ Luminal B-like/HER2+ } \\
\hline Non-immigrants & 2030/14608517 & 1.00 (ref) & $653 / 8335077$ & 1.00 (ref) \\
\hline High-income & $58 / 477618$ & $0.96(0.74-1.25)$ & $17 / 305153$ & $0.75(0.46-.21)$ \\
\hline Eastern Europe & $46 / 593550$ & $0.84(0.63-1.13)$ & $30 / 486627$ & $0.97(0.67-1.40)$ \\
\hline Middle East & $12 / 176786$ & $0.72(0.41-1.28)$ & $4 / 147450$ & $0.40(0.15-1.06)$ \\
\hline Sub-Saharan Africa & 10/152194 & $0.85(0.46-1.59)$ & $8 / 136880$ & $0.97(0.48-1.94)$ \\
\hline South Asia & 20/180867 & $1.05(0.68-1.63)$ & 17/139461 & $1.72(1.06-2.78)$ \\
\hline South-East Asia & 29/284409 & $1.03(0.71-1.49)$ & 23/232898 & $1.37(0.90-2.08)$ \\
\hline \multicolumn{5}{|l|}{ HER2+ } \\
\hline Non-immigrants & $984 / 14608517$ & 1.00 (ref) & $274 / 8335077$ & 1.00 (ref) \\
\hline High-income & $27 / 477618$ & $0.93(0.63-1.36)$ & $6 / 305153$ & $0.62(0.28-1.40)$ \\
\hline Eastern Europe & $13 / 593550$ & $0.51(0.30-0.89)$ & $6 / 486627$ & $0.45(0.20-1.01)$ \\
\hline Middle East & $6 / 176786$ & $0.79(0.35-1.76)$ & $4 / 147450$ & $0.93(0.35-2.49)$ \\
\hline Sub-Saharan Africa & $4 / 152194$ & $0.75(0.28-2.01)$ & $4 / 136880$ & $1.11(0.41-2.99)$ \\
\hline South Asia & 18/180867 & $2.02(1.26-3.23)$ & 9/139461 & $2.13(1.09-4.13)$ \\
\hline South-East Asia & $16 / 284409$ & $1.22(0.75-2.01)$ & 9/232898 & $1.24(0.64-2.42)$ \\
\hline \multicolumn{5}{|l|}{$T N B C$} \\
\hline Non-immigrants & $1886 / 14608517$ & 1.00 (ref) & $582 / 8335077$ & 1.00 (ref) \\
\hline High-income & $59 / 477618$ & $1.03(0.79-1.34)$ & 23/305153 & $1.10(0.73-1.67)$ \\
\hline Eastern Europe & $47 / 593550$ & $0.93(0.69-1.24)$ & $27 / 486627$ & $0.92(0.62-1.35)$ \\
\hline Middle East & $14 / 176786$ & $0.92(0.54-1.56)$ & $7 / 147450$ & $0.74(0.35-1.56)$ \\
\hline Sub-Saharan Africa & 9/152194 & $0.82(0.43-1.58)$ & $8 / 136880$ & $1.00(0.50-2.01)$ \\
\hline South Asia & $21 / 180867$ & $1.19(0.78-1.84)$ & 8/139461 & $0.87(0.43-1.79)$ \\
\hline South-East Asia & $14 / 284409$ & $0.54(0.32-0.91)$ & $8 / 232898$ & $0.50(0.25-1.01)$ \\
\hline
\end{tabular}


Table 2 (continued)

\begin{tabular}{|c|c|c|c|c|}
\hline & \multicolumn{2}{|l|}{ Age 20-75 } & \multicolumn{2}{|l|}{ Age 20-49 } \\
\hline & Cases/PYR & IRR (95\% CI) & Cases/PYR & IRR (95\% CI) \\
\hline \multicolumn{5}{|l|}{ Unknown } \\
\hline Non-immigrants & 2469/14608517 & 1.00 (ref) & $509 / 8335077$ & 1.00 (ref) \\
\hline High-income & $69 / 476027$ & $0.97(0.76-1.23)$ & $15 / 305153$ & $0.86(0.51-1.43)$ \\
\hline Eastern Europe & $38 / 593550$ & $0.68(0.50-0.94)$ & $13 / 486627$ & $0.55(0.32-0.96)$ \\
\hline Middle East & 9/176786 & $0.55(0.28-1.06)$ & $5 / 147450$ & $0.65(0.27-1.58)$ \\
\hline Sub-Saharan Africa & 8/152194 & $0.75(0.37-1.49)$ & $6 / 136880$ & $0.97(0.43-2.18)$ \\
\hline South Asia & 8/180867 & $0.40(0.20-0.79)$ & 1/139461 & $0.13(0.02-0.94)$ \\
\hline South-East Asia & $12 / 284409$ & $0.43(0.24-0.75)$ & $7 / 232898$ & $0.55(0.26-1.15)$ \\
\hline
\end{tabular}

PYR; person-years, IRR; incidence rate ratio, Cl; confidence interval, ref; reference, High-income; Western Europe, USA, Canada, Australia and New Zealand, Eastern Europe; Eastern Europe, Baltics and Balkan, Middle East; Middle East and North Africa

[95\% CI $0.32-0.91]$ and $20-49$ years: IRR 0.50 [95\% CI $0.25-1.01])$.

\section{Age-adjusted incidence rate ratios by grade}

For all subtypes, women aged 20-75 years from SubSaharan Africa, South Asia and South-East Asia had decreased rates of grade I and grade II tumors relative to the non-immigrant reference group (Table 3). Eastern European women also had lower rates of grade I tumors (20-75 years: IRR 0.70 (95\% CI $0.54-0.90)$. For grade III tumors, the rates across all immigrant groups were almost the same as in non-immigrants. Similar trends were observed for the luminal A-like subtype and among women aged 20-49 years.

\section{Age-adjusted incidence rate ratios by ER status}

To provide more robust estimates, we also examined whether region of birth had an effect on a cruder subtype division, simply ER status (Table 4). Sub-Saharan women had lower rates of ER+tumors compared to the non-immigrant reference groups, both within ages 20-75 years (IRR $0.5795 \%$ CI 0.42-0.77) and 20-49 years (IRR 0.66 95\% CI 0.46-0.96). South Asian (IRR 0.67 95\% CI 0.42-0.77) and South-East Asian (IRR 0.71 95\% CI 0.60-0.84) women aged 20-75 years also had lower rates of ER+tumors compared to the non-immigrant reference group, and South Asian women had a higher rate of ER- tumors, however only borderline significant (IRR 1.36 95\% CI 1.00-1.85). Women from Eastern Europe aged 20-75 years had lower rates of both ER- (IRR 0.76 95\% CI 0.60-0.98) and ER+(IRR 0.86 95\% CI 0.77-0.95) tumors, compared to the non-immigrant reference group.

\section{Sensitivity analyses by unknown subtype and young age} The proportion of unknown subtype depended on year of diagnosis and was lower in the later periods. More Asian women were diagnosed from 2010 onwards. Subtype was not available during 2005-2009 for the age group 70-75 years, which had few immigrants, so non-immigrant women had the highest proportion of unknown subtype in our data (12.5\%). In Additional file 1: Table S2 we assessed the impact of unknown subtype by restricting to the diagnosis period 2010-2015 and found estimates to be very similar to results from the full study period 2005-2015.

To minimize the possible influence of mammographic screening on our results, we assessed the effect of country of birth in a subgroup of women aged 20-40 years. The Norwegian Breast Cancer Screening Program targets women from age 50 years, and mammograms before age 45 in the Norwegian population are rare. This subgroup analysis yielded similar results as for $20-75$ years (Additional file 1: Table S3).

\section{Discussion}

We found that, in Norway, immigrant women from highincome countries had the highest incidence of breast cancer overall and of similar level as non-immigrant women. Luminal A-like breast cancer was the most common subtype regardless of region of birth. Compared to non-immigrant women, women from Eastern Europe, Sub-Saharan Africa and Asia had lower rates of the luminal A-like subtype, while Asian women had higher rates of the HER2+ subtype. The rates of TNBC tended to be similar regardless of region of birth, except in women from South-East Asia who had half the rate. Women from Sub-Saharan Africa and Asia were less likely to have grade I and grade II tumors and ER+ tumors, and women from South Asia more likely to have ER- tumors, compared to non-immigrant women. These differences were primarily driven by incidence above the age of 50 years, however, results were similar in the subgroup of women aged 20-49 years. 


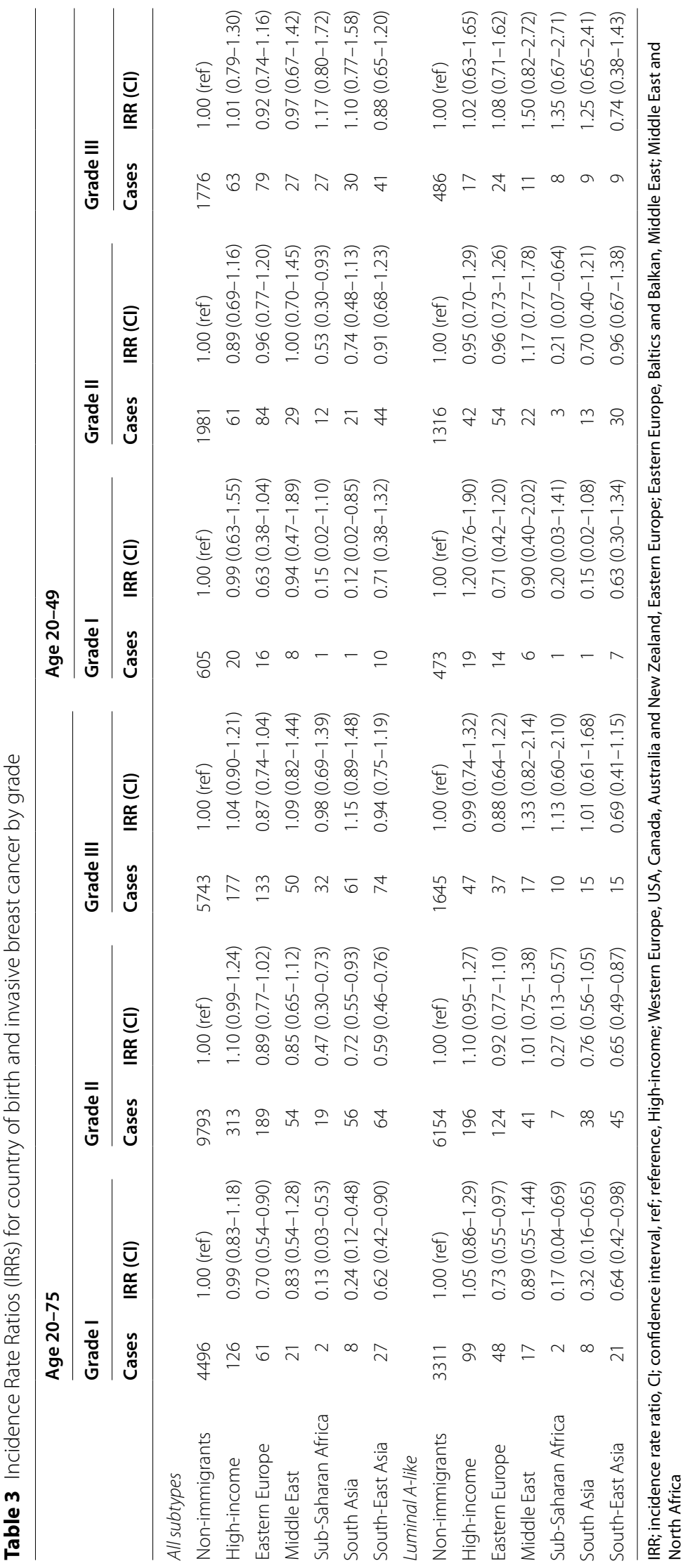


Table 4 Incidence Rate Ratios (IRRs) for country of birth and invasive breast cancer by ER status

\begin{tabular}{|c|c|c|c|c|c|c|c|c|}
\hline & \multicolumn{4}{|c|}{ Age 20-75 } & \multicolumn{4}{|c|}{ Age 20-49 } \\
\hline & \multicolumn{2}{|l|}{ ER- } & \multicolumn{2}{|l|}{ ER+ } & \multicolumn{2}{|l|}{ ER- } & \multicolumn{2}{|l|}{$\mathrm{ER}+$} \\
\hline & Cases & IRR (CI) & Cases & IRR (Cl) & Cases & IRR (CI) & Cases & IRR (CI) \\
\hline Non-immigrants & 3282 & 1.00 (ref) & 17,844 & 1.00 (ref) & 959 & 1.00 (ref) & 3645 & 1.00 (ref) \\
\hline High-income & 94 & $0.95(0.78-1.17)$ & 561 & $1.09(1.00-1.18)$ & 29 & $0.85(0.59-1.23)$ & 120 & $0.97(0.81-1.16)$ \\
\hline Eastern Europe & 66 & $0.76(0.60-0.98)$ & 336 & $0.86(0.77-0.95)$ & 35 & $0.73(0.52-1.03)$ & 155 & $0.96(0.82-1.12)$ \\
\hline Middle East & 23 & $0.89(0.59-1.34)$ & 110 & $0.95(0.78-1.14)$ & 13 & $0.85(0.49-1.47)$ & 55 & $1.03(0.79-1.34)$ \\
\hline Sub-Saharan Africa & 13 & $0.71(0.41-1.22)$ & 43 & $0.57(0.42-0.77)$ & 12 & $0.93(0.53-1.65)$ & 28 & $0.66(0.46-0.96)$ \\
\hline South Asia & 41 & $1.36(1.00-1.85)$ & 96 & $0.67(0.55-0.82)$ & 16 & $1.06(0.65-1.75)$ & 45 & $0.85(0.64-1.14)$ \\
\hline South-East Asia & 31 & $0.70(0.49-1.00)$ & 142 & $0.71(0.60-0.84)$ & 18 & $0.70(0.44-1.11)$ & 79 & $0.89(0.71-1.11)$ \\
\hline
\end{tabular}

ER; estrogen receptor, IRR; incidence rate ratio, Cl; confidence interval, ref; reference, High-income; Western Europe, USA, Canada, Australia and New Zealand, Eastern Europe; Eastern Europe, Baltics and Balkan, Middle East; Middle East and North Africa

In line with our findings, others have found that women from Western Europe are prone to the more common luminal subtypes [22], while women from Asia and Africa have lower incidence of especially the luminal A-like subtype [5, 23]. In particular, TNBC appears to be common in African women $[4,5]$, while HER2+ cancers may be more common in Asians. One study from New Zealand found Asian women to be more likely to have grade III and HER2+ breast cancers compared to women of European ancestry [24]. Another study found Arab women living in Australia to be younger and have more tumors of high grade and HER2+ subtype compared to non-immigrant women [25].

In Asian countries, incidence rates have been increasing from a young age in later cohorts, which for a while led to different age-incidence curves in Asia than in other parts of the world. This birth-cohort effect has been well described $[26,27]$ and the increase is likely partly due to changes in lifestyle over time, and partly to increased screening. Regardless, our study indicates that subtypes among the Asian immigrants in Norway are still somewhat dissimilar to non-immigrants, with more HER2+ breast cancer among Asian immigrants.

Some of the observed differences across immigrant groups described above are similar to those described across broad racial/ethnic groups (African-American, Asian-American, Hispanic and non-Hispanic White) in the U.S. [3, 7-11]. In particular, luminal cancers are more common in Non-Hispanic Whites [3, 28], African-Americans have more TNBC [28] and Asian-Americans have higher rates of HER2+ cancers $[29,30]$.

The incidence of all breast cancer subtypes increase with age, but some subtypes have less of an incline with age than others [31]. The greatest increase in incidence with age is for the ER+or luminal subtypes. This means that among young women, HER2+ and TNBC subtypes are proportionally more common [31-33]. Data from the U.S. suggest that the increase in incidence by age varies not only by subtype but also by racial/ethnic group [31, 34]. The increase in luminal subtypes by age tends to be most pronounced in non-Hispanic Whites, and could be due to a higher level of screening in non-Hispanic Whites in the U.S.

The observed differences in subtype-specific incidence across immigrant groups could, similarly to differences across racial/ethnic groups in the U.S., be due to a number of factors including variations in genetics, lifestyle, health seeking behavior or a combination. Data from the U.S. suggest that mutations in the breast cancer susceptibility genes BRCA1 and BRCA2 may be more prevalent in African-American compared to non-Hispanic White women [35], while mutations in other breast cancer genes may be less common in African-Americans [36]. There is evidence, although not completely consistent, that BRCA mutation carriers are more likely to develop TNBC $[4$, 37-39]. In our study we found similar absolute incidence of TNBC across all immigrant groups except for a lower incidence in women from Sub-Saharan Africa and SouthEast Asia. We do not know the prevalence of BRCA mutations in these breast cancer patients in Norway, however, one report found similar prevalence in Asians as in other ethnic groups [40]. Given the current state of knowledge it seems unclear how important genetic factors are for the subtype distributions we observed.

A high incidence of luminal cancers among non-immigrants and immigrants from high-income countries is probably due to a higher prevalence of classical breast cancer risk factors among these women, such as high age at first birth and low parity [20,41], as well as increased alcohol consumption and obesity [42-44]. The effects of these risk factors are not consistently limited to luminal cancers, and some, including obesity, have also been 
associated with TNBC $[6,16,45]$. However, in general both TNBC and HER2+ cancers [46] seem less strongly associated with classical reproductive factors.

Discrepancies in access to health care could also result in subtype differences across immigrant groups. A previous study using Norwegian data from 1990 to 2014 found that immigrant women from low- and middleincome countries had more advanced stage of breast cancer than non-immigrant women. The results were, however, rather consistent in women above and under 50 years of age, suggesting that screening differences do not explain these results [13]. We also did not find any effect of SES on subtype-specific incidence. However, although Norway has organized screening and public health care, immigrants still tend to have differences in the use of health care [47]. Different screening practices across immigrant groups can therefore partially have explained our findings [48-50], since luminal A-like tumors are more frequent among women with screendetected cancer [51]. On the other hand, we found results to be similar in the age group 20-49 years, an age group not offered breast cancer screening. Further, data from the Norwegian Breast Cancer Screening Program found that immigrant women from low- and middle-income countries with interval cancers were more likely to have a TNBC subtype compared to non-immigrants [52]. In addition, both among screen-detected and interval cancers, immigrants from low- and middle-income countries were more likely than non-immigrants to be diagnosed with grade 3 tumors. Thus, although we cannot exclude that part of our observed differences were due to differences in screening, we also cannot exclude the possibility that cancer may develop differently biologically in some immigrant groups.

After moving to a new country, immigrants go through different degrees of acculturation, and after one or two generations, they often adapt to the culture and lifestyle of their new home country [53]. Both lifestyle and screening participation may change with time and could contribute to more luminal cancers.

The strengths of this study include the large number of women from a geographically diverse population, maximum follow-up of 10 years, and the use of individual breast cancer subtypes. Norway has a predominantly white population with immigrants from many parts of the world. Residents have access to universal, publicly funded health care, including breast cancer screening, diagnosis and treatment.

A limitation of the study is the small number of events in some of the groups, and this produces at times uncertain effect estimates. Using more parsimonious groupings of both subtypes and countries of birth would provide more reliable results. However, as we and others have previously shown, there are substantial differences in both etiology and prognosis of cancers depending on these subtypes $[20,54,55]$ and birth country groupings [17], and we therefore believe it is important to show more detailed subgroups.

The immigrant women are on average younger than the non-immigrant women, and this difference in age distribution between the immigrant and non-immigrant groups could have affected subtype distribution. However, the results were similar in the subgroup of women aged $20-49$ years.

Time since immigration is likely important since immigration patterns to Norway have changed over time, depending mostly on the reasons for immigration (employment, family, study or seeking refuge). Immigrants in the 1970s and from 2004 and onwards were predominately workers from Pakistan, Yugoslavia and Turkey and from Poland and Lithuania, respectively. Immigrants in the 1990s and in 2015 were predominantly refugees from the Baltic countries and from Syria and Afghanistan, respectively [56, 57]. We could not adjust for time since immigration since we have relatively few cases and would need to categorize time since immigration in broad categories. Since different immigrant groups have arrived in Norway at different periods of time, country of birth is very closely linked to time since immigration, and we were therefore not able to examine effects of time since immigration and country of birth simultaneously.

Since some women had unknown subtype, the subtype-specific incidence rates are somewhat underestimated. However, the proportion with unknown subtype was small (11\%) and distributed fairly evenly across regions so we assume that missing subtype was noninformative with respect to immigrant status, and the relative effects unbiased after adjustments. We assessed the impact of unknown subtype by restricting to the diagnosis period 2010-2015 and essentially found estimates to be almost identical to the full study period 2005-2015.

Some immigrants may emigrate back to their country of birth and delay or fail to notify the Norwegian population registry, leading to an overestimation of person years and an underestimation of cancer cases. However, the registration of migration dates at Statistics Norway is generally deemed to be of high accuracy.

If an individual immigrates to Norway with a prevalent cancer, it would be registered as an incident cancer in Norway. However, only 57 immigrants in our cohort had a diagnosis of incident cancer within six months of immigration. We did censor at first emigration to avoid misclassification of individuals who got a diagnosis abroad and returned to Norway. 


\section{Conclusions}

In conclusion, we found that immigrants from Eastern Europe, Sub-Saharan Africa and Asia had lower incidence of the luminal A-like subtype, and immigrants from Asia had higher rates of HER2+tumors, compared to non-immigrants. The rates of TNBC tended to be similar regardless of region of birth, except in women from South-East Asia who had half the rate. Our findings demonstrate that it is important to include immigrant status or country of birth in ascertaining cancer outcomes. Differences in incidence rates of subtypes between immigrant groups are likely multifactorial, including genetic and social factors, lifestyle and health care seeking practices. These differences in tumor characteristics between immigrant groups should be taken into consideration when planning preventive or screening strategies.

\section{Abbreviations}

ASR: Age-standardized incidence rate; BMI: Body mass index; BRCA: Breast cancer susceptibility gene; $\mathrm{Cl}$ : Confidence interval; ER: Estrogen receptor; HER2: Human epidermal growth factor 2; ICD: International Classification of Diseases; IHC: Immunohistochemistry; IRR: Incidence rate ratio; PIN: Personal identification number; PR: Progesterone receptor; SES: Socioeconomic status; TNBC: Triple-negative breast cancer.

\section{Supplementary Information}

The online version contains supplementary material available at https://doi. org/10.1186/s13058-021-01498-5.

Additional file 1. Supplementary Tables S1-S3.

\section{Acknowledgements}

Not applicable.

\section{Authors' contributions}

All authors contributed to the study conception and design. Material preparation, data collection and analysis were performed by KVH, CBT, ALVJ and GU. The first draft of the manuscript was written by $\mathrm{KVH}$, the revised draft of the manuscript was written by ALVJ, and all authors commented on previous versions of the manuscript. All authors have read and approved the final manuscript.

\section{Funding}

This work was supported by the Norwegian Cancer Society under Grant Number 161326

\section{Availability of data and materials}

The data that support the findings of this study are available from Statistics Norway and the Cancer Registry of Norway, but restrictions apply to the availability of these data, which were used under license for the current study, and so are not publicly available. Data are however available from the authors upon reasonable request and with permission of Statistics Norway and the Cancer Registry of Norway.

\section{Declarations}

Ethics approval and consent to participate

The study was approved by the Regional Committees for Medical and Health Research Ethics (no. 2013/2376-17).

\section{Consent for publication}

Not applicable.

\section{Competing interests}

The authors declare that they have no competing interests.

\section{Author details}

${ }^{1}$ Department of Registration, Cancer Registry of Norway, Oslo, Norway. ${ }^{2}$ Department of Medical Epidemiology and Biostatistics, Karolinska Institute, 17177 Stockholm, Sweden. ${ }^{3}$ Cancer Registry of Norway, Postbox 5313 0304 Majorstuen, Oslo, Norway. ${ }^{4}$ Department of Cancer Genetics, Institute for Cancer Research, Oslo University Hospital, 0424 Oslo, Norway. ${ }^{5}$ Department of Pathology, Oslo University Hospital, 0424 Oslo, Norway. ${ }^{6}$ Department of Preventive Medicine, Keck School of Medicine, University of Southern California, Los Angeles, CA, USA. ${ }^{7}$ Department of Nutrition, Institute of Basic Medical Sciences, University of Oslo, Oslo, Norway.

Received: 20 October 2020 Accepted: 20 December 2021

Published online: 10 January 2022

\section{References}

1. International Agency for Research on Cancer. Global Cancer Observatory. http://gco.iarc.fr/. Accessed 31 Aug 2020

2. Sørlie T, Perou CM, Tibshirani R, Aas T, Geisler S, Johnsen H, et al. Gene expression patterns of breast carcinomas distinguish tumor subclasses with clinical implications. Proc Natl Acad Sci USA. 2001;98(19):10869-74

3. Carey LA, Perou CM, Livasy CA, Dressler LG, Cowan D, Conway K, et al. Race, breast cancer subtypes, and survival in the Carolina Breast Cancer Study. JAMA. 2006;295(21):2492-502.

4. Amankwaa-Frempong E, Yeboah FA, Nguah SB, Newman LA. Breast cancer genetic testing among African patients with breast cancer: deoxyribonucleic acid extraction from tumor tissue and international multidisciplinary partnerships. JAMA Surg. 2017:152(8):800-1.

5. Huo D, Ikpatt F, Khramtsov A, Dangou JM, Nanda R, Dignam J, et al. Population differences in breast cancer: survey in indigenous African women reveals over-representation of triple-negative breast cancer. J Clin Oncol. 2009;27(27):4515-21.

6. Bauer KR, Brown M, Cress RD, Parise CA, Caggiano V. Descriptive analysis of estrogen receptor (ER)-negative, progesterone receptor (PR)-negative, and HER2-negative invasive breast cancer, the so-called triple-negative phenotype: a population-based study from the California cancer Registry. Cancer. 2007;109(9):1721-8.

7. Hausauer AK, Keegan TH, Chang ET, Clarke CA. Recent breast cancer trends among Asian/Pacific Islander, Hispanic, and African-American women in the US: changes by tumor subtype. Breast Cancer Res. 2007;9(6):R90.

8. Deshpande AD, Jeffe DB, Gnerlich J, lqbal AZ, Thummalakunta A, Margenthaler JA. Racial disparities in breast cancer survival: an analysis by age and stage. J Surg Res. 2009;153(1):105-13.

9. Miller BA, Chu KC, Hankey BF, Ries LA. Cancer incidence and mortality patterns among specific Asian and Pacific Islander populations in the U.S. Cancer Causes Control. 2008;19(3):227-56

10. Clarke CA, Keegan TH, Yang J, Press DJ, Kurian AW, Patel AH, et al. Agespecific incidence of breast cancer subtypes: understanding the blackwhite crossover. J Natl Cancer Inst. 2012;104(14):1094-101.

11. Gomez SL, Von Behren J, McKinley M, Clarke CA, Shariff-Marco S, Cheng I, et al. Breast cancer in Asian Americans in California, 1988-2013: increasing incidence trends and recent data on breast cancer subtypes. Breast Cancer Res Treat. 2017;164(1):139-47.

12. Trewin CB, Hjerkind KV, Johansson ALV, Strand BH, Kiserud CE, Ursin G. Socioeconomic inequalities in stage-specific breast cancer incidence: a nationwide registry study of 1.1 million young women in Norway, 2000-2015. Acta Oncol. 2020;59(11):1284-90.

13. Thogersen $\mathrm{H}$, Moller B, Robsahm TE, Aaserud S, Babigumira R, Larsen IK. Comparison of cancer stage distribution in the immigrant and host populations of Norway, 1990-2014. Int J Cancer. 2017;141(1):52-61.

14. Preat F, Simon P, Noel JC. Differences in breast carcinoma immunohistochemical subtypes between immigrant Arab and European women. Diagn Pathol. 2014;9:26. 
15. Menashe I, Anderson WF, Jatoi I, Rosenberg PS. Underlying causes of the black-white racial disparity in breast cancer mortality: a population-based analysis. J Natl Cancer Inst. 2009;101(14):993-1000.

16. Vona-Davis $L$, Rose DP. The influence of socioeconomic disparities on breast cancer tumor biology and prognosis: a review. J Womens Health (Larchmt). 2009;18(6):883-93.

17. Hjerkind KV, Qureshi SA, Moller B, Weiderpass E, Deapen D, Kumar B, et al. Ethnic differences in the incidence of cancer in Norway. Int J Cancer. 2017;140(8):1770-80

18. Larsen IK, Smastuen M, Johannesen TB, Langmark F, Parkin DM, Bray F, et al. Data quality at the Cancer Registry of Norway: an overview of comparability, completeness, validity and timeliness. Eur J Cancer. 2009:45(7):1218-31.

19. Goldhirsch A, Winer EP, Coates AS, Gelber RD, Piccart-Gebhart M, Thurlimann B, et al. Personalizing the treatment of women with early breast cancer: highlights of the St Gallen International Expert Consensus on the Primary Therapy of Early Breast Cancer 2013. Annal Oncol. 2013;24(9):2206-23.

20. Ellingjord-Dale M, Vos L, Tretli S, Hofvind S, Dos-Santos-Silva I, Ursin G. Parity, hormones and breast cancer subtypes - results from a large nested case-control study in a national screening program. Breast Cancer Res. 2017;19(1):10.

21. Breslow N, Day D. Chapter 2: rates and rate standardization. In: Statistical methods in cancer research. Volume II - the analysis of cohort studies. IARC Scientfic Publications No. 82. (Oxford University Press, Oxford, 1987). pp. 48-79.

22. Spitale A, Mazzola P, Soldini D, Mazzucchelli L, Bordoni A. Breast cancer classification according to immunohistochemical markers: clinicopathologic features and short-term survival analysis in a population-based study from the South of Switzerland. Ann Oncol. 2009;20(4):628-35.

23. Huang X, Dugo M, Callari M, Sandri M, De Cecco L, Valeri B, et al. Molecular portrait of breast cancer in China reveals comprehensive transcriptomic likeness to Caucasian breast cancer and low prevalence of luminal A subtype. Cancer Med. 2015;4(7):1016-30.

24. Lao C, Lawrenson R, Edwards M, Campbell I. Treatment and survival of Asian women diagnosed with breast cancer in New Zealand. Breast Cancer Res Treat. 2019;177(2):497-505

25. Heilat GB, Brennan ME, Kanesalingam K, Sriram N, Meybodi F, French J. Presentation, tumour and treatment features in immigrant women from Arabic-speaking countries treated for breast cancer in Australia. ANZ J Surg. 2020;90(3):325-31.

26. Mubarik S, Malik SS, Wang Z, Li C, Fawad M, Yu C. Recent insights into breast cancer incidence trends among four Asian countries using ageperiod-cohort model. Cancer Manag Res. 2019;11:8145-55.

27. Sung H, Rosenberg PS, Chen WQ, Hartman M, Lim WY, Chia KS, et al. Female breast cancer incidence among Asian and Western populations: more similar than expected. J Natl Cancer Inst. 2015;107(7).

28. Kong X, Liu Z, Cheng R, Sun L, Huang S, Fang Y, Wang J. Variation in breast cancer subtype incidence and distribution by race/ethnicity in the United States from 2010 to 2015. JAMA Netw Open. 2020; 3(10): e2020303.

29. Telli ML, Chang ET, Kurian AW, Keegan TH, McClure LA, Lichtensztajn D, et al. Asian ethnicity and breast cancer subtypes: a study from the California Cancer Registry. Breast Cancer Res Treat. 2011;127(2):471-8.

30. Kurian AW, Fish K, Shema SJ, Clarke CA. Lifetime risks of specific breast cancer subtypes among women in four racial/ethnic groups. Breast Cancer Res. 2010;12(6):R99.

31. National Cancer Institute. Surveillance, Epidemiology, End Results Program. SEER*Explorer. https://seer.cancer.gov/explorer/application. html?site $=622 \&$ data_type $=1 \&$ graph_type $=3 \&$ compareBy $=$ race $\&$ chk_race_1 1 1\&hdn_rate_type $=1 \&$ hdn_sex $=3 \&$ advopt_precision $=1 \&$ advopt_show_ci=on\&advopt_display=2. Accessed 12 Aug 2021

32. Neven $P$, Van Calster B, Van den Bempt I, Van Huffel S, Van Belle V, Hendrickx W, et al. Age interacts with the expression of steroid and HER-2 receptors in operable invasive breast cancer. Breast Cancer Res Treat. 2008;110(1):153-9.

33. Kheirelseid EH, Boggs JM, Curran C, Glynn RW, Dooley C, Sweeney KJ et al. Younger age as a prognostic indicator in breast cancer: a cohort study. BMC Cancer. 2011;11:383.

34. Parise CA, Bauer KR, Caggiano V. Variation in breast cancer subtypes with age and race/ethnicity. Crit Rev Oncol Hematol. 2010;76(1):44-52.
35. Pal T, Bonner D, Cragun D, Monteiro AN, Phelan C, Servais L, et al. A high frequency of BRCA mutations in young black women with breast cancer residing in Florida. Cancer. 2015;121(23):4173-80.

36. Domchek SM, Yao S, Chen F, Hu C, Hart SN, Goldgar DE, et al. Comparison of the prevalence of pathogenic variants in cancer susceptibility genes in Black women and non-Hispanic White women with breast cancer in the United States. JAMA Oncol. 2021;7(7):1045-50.

37. Kurian AW. BRCA1 and BRCA2 mutations across race and ethnicity: distribution and clinical implications. Curr Opin Obstet Gynecol. 2010;22(1):72-8.

38. Haffty BG, Choi DH, Goyal S, Silber A, Ranieri K, Matloff E, et al. Breast cancer in young women (YBC): prevalence of BRCA1/2 mutations and risk of secondary malignancies across diverse racial groups. Ann Oncol. 2009;20(10):1653-9.

39. Oluwagbemiga LA, Oluwole A, Kayode AA. Seventeen years after BRCA1: what is the BRCA mutation status of the breast cancer patients in Africa? a systematic review. Springerplus. 2012;1(1):83.

40. Kwong A, Shin VY, Ho JC, Kang E, Nakamura S, Teo SH, et al. Comprehensive spectrum of BRCA1 and BRCA2 deleterious mutations in breast cancer in Asian countries. J Med Genet. 2016:53(1):15-23.

41. Anderson KN, Schwab RB, Martinez ME. Reproductive risk factors and breast cancer subtypes: a review of the literature. Breast Cancer Res Treat. 2014;144(1):1-10.

42. Suzuki R, Orsini N, Saji S, Key TJ, Wolk A. Body weight and incidence of breast cancer defined by estrogen and progesterone receptor status - a meta-analysis. Int J Cancer. 2009;124(3):698-712.

43. Ellingjord-Dale M, Vos L, Hjerkind KV, Hjartåker A, Russnes HG, Tretli $\mathrm{S}$, et al. Alcohol, physical activity, smoking, and breast cancer subtypes in a large, nested case-control study from the Norwegian breast cancer screening program. Cancer Epidemiol Biomarkers Prev. 2017;26(12):1736-44

44. Ellingjord-Dale M, Christakoudi S, Weiderpass E, Panico S, Dossus L, Olsen A, et al. Long-term weight change and risk of breast cancer in the European Prospective Investigation into Cancer and Nutrition (EPIC) study. Int J Epidemiol. 2021

45. Trivers KF, Lund MJ, Porter PL, Liff JM, Flagg EW, Coates RJ, et al. The epidemiology of triple-negative breast cancer, including race. Cancer Causes Control. 2009:20(7):1071-82.

46. Yang XR, Chang-Claude J, Goode EL, Couch FJ, Nevanlinna H, Milne RL, et al. Associations of breast cancer risk factors with tumor subtypes: a pooled analysis from the Breast Cancer Association Consortium studies. J Natl Cancer Inst. 2011;103(3):250-63.

47. Diaz E, Mbanya VN, Gele AA, Kumar B. Differences in primary health care use among sub-Saharan African immigrants in Norway: a register-based study. BMC Health Serv Res. 2017;17(1):509.

48. Leinonen MK, Campbell S, Ursin G, Trope A, Nygard M. Barriers to cervical cancer screening faced by immigrants: a registry-based study of 1.4 million women in Norway. Eur J Public Health. 2017;27(5):873-9.

49. Moen KA, Kumar B, Qureshi S, Diaz E. Differences in cervical cancer screening between immigrants and nonimmigrants in Norway: a primary healthcare register-based study. Eur J Cancer Prev. 2017;26(6):521-7.

50. Bhargava S, Mangerud G, Hofvind S. Attendance in BreastScreen Norway among immigrant and Norwegian-born women. Tidsskr Nor Laegeforen. 2021;141(2).

51. Hofvind S, Holen Å, Román M, Sebuødegård S, Puig-Vives M, Akslen L. Mode of detection: an independent prognostic factor for women with breast cancer. J Med Screen. 2015;23(2):89-97.

52. Bhargava S, Akslen LA, Bukholm IRK, Hofvind S. Performance measures among non-immigrants and immigrants attending BreastScreen Norway: a population-based screening programme. Eur Radiol. 2019;29(9):4833-42.

53. Ziegler RG, Hoover RN, Nomura AM, West DW, Wu AH, Pike MC, et al. Relative weight, weight change, height, and breast cancer risk in AsianAmerican women. J Natl Cancer Inst. 1996;88(10):650-60.

54. Johansson ALV, Trewin CB, Fredriksson I, Reinertsen KV, Russnes H, Ursin G. In modern times, how important are breast cancer stage, grade and receptor subtype for survival: a population-based cohort study. Breast Cancer Res. 2021;23(1):17.

55. Parise CA, Caggiano V. Breast Cancer Survival Defined by the ER/PR/ HER2 Subtypes and a Surrogate Classification according to Tumor 
Grade and Immunohistochemical Biomarkers. J Cancer Epidemiol. 2014;2014:469251.

56. Statistics Norway; Immigrants by reason for immigration, updated 13 May 2019. http://www.ssb.no/en/innvgrunn/. Accessed on 28 Mar 2020.

57. Statistics Norway. https://www.ssb.no/innvandring-og-innvandrere/fakta side/innvandring. Accessed 14 Apr 2021

\section{Publisher's Note}

Springer Nature remains neutral with regard to jurisdictional claims in published maps and institutional affiliations.

- fast, convenient online submission

- thorough peer review by experienced researchers in your field

- rapid publication on acceptance

- support for research data, including large and complex data types

- gold Open Access which fosters wider collaboration and increased citations

- maximum visibility for your research: over 100M website views per year

At BMC, research is always in progress.

Learn more biomedcentral.com/submissions 